\title{
Applying Clustering Coefficient to the Pattern of International Author Collaboration in Anesthesiology
}

\author{
Hsien-Yi Wang', Tsair-Wei Chien ${ }^{2}$, Julie Chi $\mathrm{Chow}^{3}$, Willy Chou ${ }^{4,5 *}$ \\ ${ }^{1,5}$ NephrologyDepartment, Chi-Mei Medical Center, Tainan, Taiwan \\ ${ }^{2}$ Research Department, Chi-Mei Medical Center, Tainan, Taiwan \\ ${ }^{3}$ Department of Pediatrics, Chi Mei medical center, Tainan, Taiwan \\ ${ }^{4}$ Department of physical medicine and rehabilitation, Chi Mei medical center, Tainan, Taiwan \\ ${ }^{5}$ Department of Recreation and Health-Care Management \& Institute of recreation Industry Management, Chia \\ Nan University of Pharmacy, Tainan, Taiwan
}

*Corresponding Author: Willy Chou, Department of physical medicine and rehabilitation, Chi Mei medical center, Tainan, Taiwan,Email: ufan0101@ms22.hinet.net

\begin{abstract}
Objective: To apply cluster coefficient (CC) to the pattern of international author collaborations in anesthesiology using data from Medline and to visualize results by means of Google maps and social network analysis(SNA).
\end{abstract}

Methods: Selecting 9,598 abstracts, author names, countries, and keywords on December 20, 2017 from Medline based on journal of anesthesiology since 1987, we reported following features: (1) nation distribution for $1^{\text {st }}$ author's nationality; (2) eminent authors in the field of anesthesiology, (3) notable keywords with Medical subject heading (MESH) terms representing anesthesiology, and (4) cluster coefficients in networks. We programmed Microsoft Excel VBA routines to extract data from Medline. Google Maps and SNAPajek software were performed to display graphical representations with an easy-to-read feature for readers.

Results: We found that (1) the most number of papers in surgery are from U.S.(5147, 53.63 \%) and Japan( 660, 6.88\%); (2) the productive authors in anesthesiology are Daniel Sessler(Russia) and Nichilas Dalesio (Spain); (3) the most linked MESH terms are halothane/*pharmacology and isoflurane/*analogs \& derivatives/*pharmacology; (4)author networks present higher CC than those MESH networks. .

Conclusions: Social network analysis provides wide and deep insight into the relationships among nations, coauthor collaborations, and MESH terms. The results can be provided to readers for future submission to journal in anesthesiology.

Keywords: abstract keywords, authorship collaboration, Google Maps, social network analysis, Medline

\section{INTRODUCTION}

Anesthesiology describes the medical specialty concerned with the study of anesthesia or anesthetics. The American Society of Anesthesiologists define anesthesiology as "the practice of medicine dedicated to the relief of pain and total care of the surgical patient before, during and after surgery"[1]. Anesthesia is the loss of sensation with or without the loss of consciousness.

As of December20, 2017, more than 176,977 papers were found on Pubmed.comby searching for the keyword anesthesiology and 3,124in the paper title only including anesthesiology. The journal of Anesthesiology has published 23,900 articles since 1987. However, which nations dominate the papers published in Anesthesiology remains unknown and which keywords included in papers of anesthesiology were frequently appeared in past decades is still unclear.

Big Data is a concept that has evolved from the modern trend of "scientism"[2]. Many data scientists' develop ways to discover new 
knowledge from the vast quantities of increasingly available information [2].An apocryphal story was often told to tell us the concept of co-occurrence that is about beer and diaper sales. It usually goes along with both beer and diaper sales with a strong correlation on Friday [3-5]. All possible pairs of our observed goods shown on customers' receipts are worth studying the association of goods, which is similar to the keywords and authors in journal papers. Social network analysis (SNA) [6-8] is one methodology for analyzing big data and investigating the association of any pairs of goods in a network.

Authorship collaboration using SNA is an example many authors researched in recent years [6] because co-authors among researchers form is a type of social network. Whether the keyword network in anesthesiology earns a higher centrality measure (or say density) than the author network is required to explore. We are thus interested in using SNA to explore the features in anesthesiology from published papers we observed in Medline library.

Google maps provide an overall view of geospatial visualization with coordinates of latitude and longitude on a map $[9,10]$. However, few papers were found in Medline library in a search of keyword google map [Title] on November 22, 2017. Many papers [68,11 ] have studied on co-author collaboration in academics, however, none display results with the skill of incorporating Google maps into social network analysis.

Our aims are to apply clustering coefficient[12] to the pattern of international author collaboration in anesthesiology on the following topics: (i) nation distribution;(ii) the most eminent authors in anesthesiology; (iii) the recent research domains defined by MESH (medical subject headings) terms; (iv)the cluster coefficients in different networks.

\section{METHODS}

\subsection{Data Sources}

We programmed Microsoft Excel VBA (visual basic for applications) modules to extract abstracts and their corresponding coauthor names as well as author-defined keywords for each article on December 20, 2017 from Medicine National Institutes of Health (Medline) since 1987. Only those abstracts published by the keyword anesthesiology [journal] and labeled with Journal Article were included. Others like those labeled with Published Erratum, Editorial or without author nation name were excluded from this study. A total of 9, 598 eligible abstracts were obtained from Medline.

\subsection{Data Arrangement to Fit Sna Requirement}

Prior to visualize our results using SNA, we organized data in compliance with the format and guidelines defined by Pajeksoftware[13]. Microsoft Excel VBA was used to deal with data fitting to the SNA requirement.

\subsection{Graphical Representations to Report}

\section{(1) Author nations and their relations}

A table (i.e., columns for publication years and rows for the $1^{\text {st }}$ author nations) was made for presenting the distribution of nations regrading surgery. The bigger bubble means the more number of the nodes (i.e., nations, or keywords in this study). The wider line indicates the stronger relations between two nodes. Community clusters are filled with different colors in bubbles.

\section{(2)Keywords to present the research domain}

If keywords represent the research domain, the stronger relations between two keywords can be highlighted and linked by SNA, like the concept of co-occurrence about beer and diaper sales. The presentation for the bubble and line is interpreted similar to the previous section. Medical subject heading (MESH) terms were applied to represent the keywords in the current study.

\subsection{Statistical Tools and Data Analyses}

Google Maps [14] and SNA Pajeksoftware[13] were used to display visualized representations for eminent authors and keywords in relation with anesthesiology. Author-made Excel VBA modules were applied to organize data. Cluster coefficient represents the density of a network as below: $=$

$$
\frac{\text { number of closed troplets }}{\text { number of possibleconnected triplets of nodes }}=\frac{\sum_{i=1}^{n} \text { other } \text { two_nodes }_{i} \text { connected }}{\sum_{i=1}^{n}\left(m_{i} *\left(m_{i}-1\right) / 2\right.}
$$

, whereas $n=$ the number of nodes in a network and $m=$ the number of other connected nodes with a specific ego node. A significant lever $(>1.96)$ is defined by $\mathrm{t}$-value as the formula $\left[=\mathrm{cc} * \sqrt{ }\left[(\mathrm{n}-2) /\left(1-\mathrm{cc}^{2}\right)\right]\right.$.

In contrast, E-I index is defined by the formula of $\frac{E L-I L}{E L+I L}$, where $E L=$ hte number of external friendshio links and $\mathrm{IL}=$ the number of internal 
friendship links [15]. The negative E-I index means a coherence cluster in existence. Similarly, the higher $\mathrm{CC}$ indicates many members are other linked members' friends. Density is defined as the ratio of the linked members over all possible linked members.

\section{RESUlts}

\subsection{Author Nations and Their Relations}

A total of 9,598 eligible papers with complete author nations based on journal article since 1997 are shown in Table 1. We can see that the most number of papers are from nations of U.S.(5147,53.63 \%) and Japan(660,6.88\%). The trend in the number of publications with authorship from countries is present in the column of growth in Table 1. All continents but Europe and Africa present a positively increase.

The diagram shown by SNA and Google Maps in Figure 1displays author collaboration among nations based on the journal of anesthesiology. Overall, the highest productive nations are from

Table1. Nation distribution based on the $1^{\text {st }}$ author for papers published in biostatistics

\begin{tabular}{|c|c|c|c|c|c|c|c|c|c|c|c|c|c|c|}
\hline Nation/Continer & 1987-2007 & 2008 & 2009 & 2010 & 2011 & 2012 & 2013 & 2014 & 2015 & 2016 & 2017 & Total & & Growth \\
\hline \begin{tabular}{|l|} 
AFRICA \\
\end{tabular} & 3 & & & 1 & & 1 & 1 & & 1 & & & 7 & 0.07 & 0.00 \\
\hline Mali & 1 & & & & & & 1 & & 1 & & & 3 & 0.03 & 0.26 \\
\hline Egypt & 0 & & & 1 & & 1 & & & & & & 2 & 0.02 & -0.26 \\
\hline Other & 2 & & & & & & & & & & & 2 & 0.02 & - \\
\hline Asia & 702 & 30 & 30 & 29 & 27 & 27 & 25 & 38 & 36 & 32 & 38 & 1018 & 10.61 & 0.60 \\
\hline Japan & 546 & 15 & 19 & 11 & 10 & 8 & 8 & 15 & 8 & 7 & 11 & 660 & 6.88 & -0.56 \\
\hline China & 20 & 6 & 5 & 8 & 9 & 10 & 13 & 20 & 17 & 17 & 19 & 145 & 1.51 & 0.93 \\
\hline Taiwan & 28 & 2 & 3 & 6 & 5 & 3 & 1 & 2 & 6 & 3 & 3 & 62 & 0.65 & -0.02 \\
\hline Israel & 35 & 3 & & 1 & 2 & 1 & & & & 2 & & 45 & 0.47 & -0.42 \\
\hline Hong Kong & 23 & 1 & 1 & 1 & & 2 & 1 & 1 & 3 & 1 & 2 & 36 & 0.38 & 0.47 \\
\hline Others & 50 & 3 & 2 & 2 & 1 & 3 & 2 & 0 & 2 & 2 & 3 & 70 & 0.73 & -0.08 \\
\hline EUROPE & 1882 & 75 & 100 & 92 & 74 & 80 & 78 & 94 & 77 & 74 & 77 & 2711 & 28.25 & -0.35 \\
\hline France & 385 & 17 & 18 & 24 & 23 & 32 & 14 & 24 & 13 & 12 & 22 & 585 & 6.10 & -0.20 \\
\hline Germany & 400 & 19 & 26 & 10 & 16 & 10 & 13 & 18 & 13 & 14 & 13 & 553 & 5.76 & -0.43 \\
\hline U.K & 217 & 4 & 6 & 3 & 3 & 4 & 11 & 5 & 9 & 10 & 9 & 282 & 2.94 & 0.70 \\
\hline Netherlands & 149 & 10 & 10 & 13 & 10 & 10 & 5 & 10 & 9 & 8 & 12 & 246 & 2.56 & -0.18 \\
\hline Switzerland & 121 & 2 & 13 & 10 & 4 & 6 & 6 & 6 & 2 & 6 & 3 & 180 & 1.88 & -0.39 \\
\hline Others & 268 & 11 & 16 & 16 & 8 & 9 & 17 & 12 & 9 & 6 & 7 & 381 & 3.97 & -0.55 \\
\hline N. AMERICA & 4045 & 128 & 138 & 145 & 153 & 125 & 134 & 179 & 174 & 210 & 197 & 5646 & 58.82 & 0.83 \\
\hline U.S & 3717 & 114 & 120 & 131 & 142 & 109 & 125 & 160 & 156 & 180 & 176 & 5147 & 53.63 & 0.84 \\
\hline Canada & 321 & 14 & 18 & 14 & 11 & 16 & 9 & 19 & 18 & 30 & 21 & 492 & 5.13 & 0.58 \\
\hline Others & 7 & 0 & 0 & 0 & 0 & 0 & 0 & 0 & 0 & 0 & 0 & 7 & 0.07293 & - \\
\hline OCEANIA & 95 & 5 & 7 & 8 & 3 & 2 & 6 & 7 & 10 & 11 & 9 & 164 & 1.71 & 0.57 \\
\hline Australia & 86 & 4 & 6 & 6 & 3 & 2 & 6 & 5 & 7 & 8 & 7 & 141 & 1.47 & 0.54 \\
\hline New Zealand & 9 & 1 & 1 & 2 & & & & 2 & 3 & 3 & 2 & 23 & 0.24 & 0.53 \\
\hline S. AMERICA & 37 & 1 & & & 1 & 2 & 1 & 1 & 5 & 2 & 2 & 52 & 0.54 & 0.60 \\
\hline Brazil & 15 & 1 & & & & 2 & 1 & 1 & 3 & 2 & 1 & 26 & 0.27 & 0.57 \\
\hline Others & 22 & 0 & 0 & 0 & 1 & 0 & 0 & 0 & 2 & 0 & 1 & 26 & 0.27089 & 0.42 \\
\hline Total & 6764 & 239 & 275 & 275 & 258 & 237 & 245 & 319 & 303 & 329 & 323 & 9598 & 100.00 & 0.75 \\
\hline
\end{tabular}

U.S. and Europe, see Figure 1. Any nation collaborated with other nations are shown with a blue line. Interested authors are recommend to click the bubble of interest to see details on a website at reference [18].

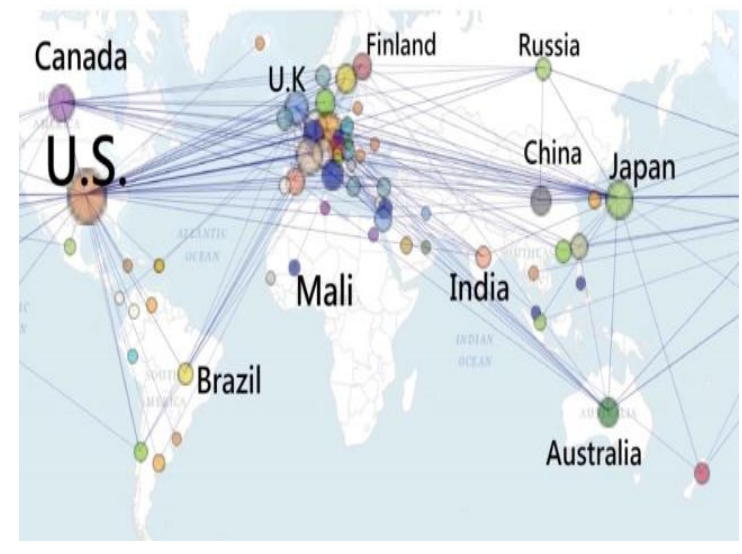

Figure1. Google Maps on the topic of author collaboration in anesthesiology $(C C=0.86)$ 


\subsection{The Eminent Authors in Surgery}

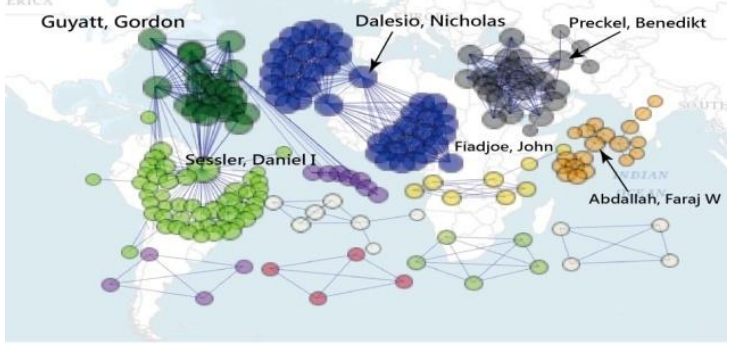

Figure2. Google Maps on eminent authors in anesthesiology $(C C=0.95)$

The most eminent authors who published most number of papers in anesthesiology are Daniel Sessler (Russia) and NichilasDalesio (Spain), see Figure 2. The link on website was referred to reference [16]

\subsection{Keywords to Present the Research Domain of Anesthesiology Recently}

The most linked MESH termsarehalothane/* pharmacology and isoflurane/*analogs \& derivatives/*pharmacology, see Figure 3 or click it on the reference [17]. We can see that the
MESH terms consisting of many clusters with different cluster coefficients.

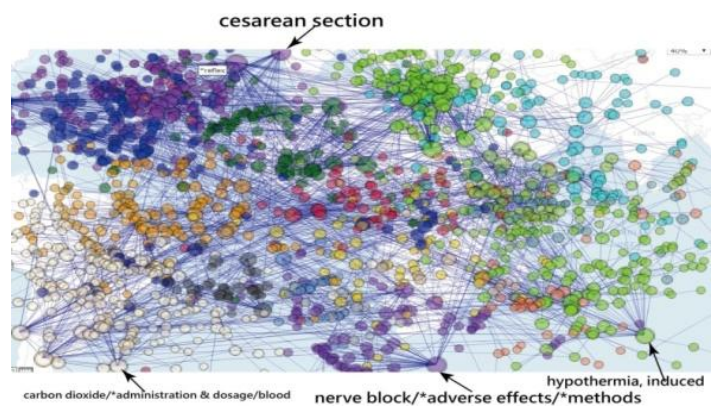

Figure3. Google Maps on MESH terms in anesthesiology $(C C=0.60)$

\subsection{Cluster Coefficients in a Network}

Each cluster has its own cluster coefficient representing the density of a network. We found that author clusters earn higher CC than have MESH clusters. Cluster coefficient has a significant effect in comparison with a significant t-value (>2.0), indicating author network with more significance than those MESH terms (Table 2).

Table2. Cluster coefficients in each cluster and their relevant indicators

\begin{tabular}{|c|c|c|c|c|c|}
\hline Name & $\mathbf{C C}$ & EI & node & degree & t-value \\
\hline fentanyl/*administration \&\#38; dosage/blood & 0.60 & -0.85 & 16 & 25 & $2.81 *$ \\
\hline malignant hyperthermia/*complications/diagnosis & 0.53 & -0.88 & 6 & 8 & 1.25 \\
\hline *laryngoscopes & 0.19 & -0.79 & 22 & 26 & 0.87 \\
\hline anesthetics, local/*administration \&\#38; dosage & 0.17 & -0.47 & 91 & 126 & 1.63 \\
\hline *anesthesia and analgesia & 0.13 & -0.42 & 81 & 125 & 1.17 \\
\hline *biomedical research & 0.13 & -0.55 & 146 & 322 & 1.57 \\
\hline anesthesia, inhalation/*instrumentation & 0.13 & -0.81 & 55 & 67 & 0.95 \\
\hline pain, postoperative/*diagnosis/*drug therapy & 0.12 & -0.66 & 107 & 159 & 1.24 \\
\hline *hypothermia, induced & 0.12 & -0.52 & 126 & 166 & 1.35 \\
\hline *analgesia, epidural & 0.10 & -0.57 & 35 & 53 & 0.58 \\
\hline *anesthesiology & 0.08 & -0.52 & 188 & 279 & 1.09 \\
\hline oxygen/*administration \&\#38; dosage/adverse effects/blood & 0.07 & -0.33 & 94 & 121 & 0.67 \\
\hline *respiration, artificial & 0.07 & -0.46 & 61 & 72 & 0.54 \\
\hline *preanesthetic medication & 0.07 & -0.59 & 124 & 168 & 0.78 \\
\hline anesthesia, general/*adverse effects/*methods & 0.06 & -0.66 & 92 & 107 & 0.57 \\
\hline pulmonary alveoli/*analysis/metabolism & 0.06 & -0.50 & 16 & 18 & 0.22 \\
\hline *needles & 0.06 & -0.56 & 33 & 35 & 0.33 \\
\hline \multicolumn{6}{|l|}{ Author } \\
\hline Chong, Carol P W & 0.95 & -0.70 & 7 & 20 & 1.04 \\
\hline Beach, Michael L & 0.83 & -1.00 & 4 & 6 & $2.52 *$ \\
\hline Ahlstrand, Rebecca & 0.67 & -1.00 & 4 & 6 & $2.87 *$ \\
\hline Preckel, Benedikt & 0.59 & -1.00 & 25 & 217 & $3.50 *$ \\
\hline Goobie, Susan M & 0.59 & -0.82 & 20 & 190 & $3.10^{*}$ \\
\hline Peelen, Linda M & 0.56 & -1.00 & 8 & 17 & 1.85 \\
\hline Szmuk, Peter & 0.54 & -0.85 & 22 & 231 & $6.80 *$ \\
\hline Chan, Matthew T V & 0.50 & -0.85 & 21 & 210 & 1.66 \\
\hline Auyong, David B & 0.50 & -1.00 & 5 & 10 & 0.43 \\
\hline Abdallah, Faraj W & 0.41 & -1.00 & 19 & 37 & 1.00 \\
\hline Fox, Amanda A & 0.19 & -1.00 & 7 & 11 & 0.24 \\
\hline Abriel, Hugues & 0.17 & -1.00 & 4 & 6 & 1.28 \\
\hline Sessler, Daniel I & 0.15 & -0.80 & 49 & 123 & $2.10 *$ \\
\hline
\end{tabular}




\section{DISCUSSION}

This study found that (1) the most number of papers in surgery are from U.S.( 5147, $53.63 \%$ ) and $\operatorname{Japan}(660,6.88 \%$ ); (2) the productive authors in anesthesiology are Daniel Sessler(Russia) and NichilasDalesio(Spain); (3) the most linked MESH terms are halothane/* pharmacology and isoflurane/*analogs \& derivatives/*pharmacology; (4)author networks present higher CC than those MESH networks.

\section{What This Adds to What Was Known}

Many previous researches [6-8] have investigated coauthor collaboration using social network analysis. The results(the most number of articles in anesthesiology from U.S. and Europe) are similar to the findings that dominant nations in science come from U.S. and Europe[19,20].Referring to the apocryphal story told to discover the co-occurrence about beer and diaper sales[3-5], we showed a novel method incorporating SNA with Google maps to explore the data. It can be seen that visual representations rendered to readership is rare in literature. Traditionally, it is very hard to observe the association of two or more symptoms or entities together appeared in a network at a moment.

Journal authorship collaboration can be compared with each other using Google Maps. We can see that many links connecting two nations which indicate a collaboration pattern in paper publication similar to the previous study [4]. Hence the researchers have a high level of international author collaboration in anesthesiology, which is inconsistent with the previous studies that investigated scientific collaboration of Iranian Psychology and Psychiatry Researchers [21, 22].

There are 1,084 papers with the keyword social network analysis in paper title when searching Medline in December21, 2017. There were two papers $[23,24]$ incorporated MESH into social network analysis to release relevant knowledge to readers. However, no any that can incorporate Google maps link we used in the current study. The CCs we illustrated in reference [16-18] are called overall CCs. The highest cluster in figures are $0.86,0.95$ and 0.60 , respectively. Different form of global CCs or or individual $\mathrm{CC}$ are defined by each cluster or by each node. Evidence suggests that in most real-world networks, nodes tend to create tightly knit groups characterized by a relatively high density of ties; this likelihood tends to be greater than the average probability of a tie randomly established between two nodes [25, 26].

\section{What It Implies and What Should Be Changed?}

Scientific publication is one of the objective measurements to evaluate the achievements of a medical specialty or discipline [27]. It is worth using SNA and Google Maps to explore knowledge to readers in future.

Many algorithms and measures (or indicators) have been developed using SNA to graphically explore data. If we investigate whether any author or paper most fits the research domain of a target journal, the centrality measures can be used [6]. It means that the core subject can be analyzed using the centrality measure [22, 28] yielded by SNA.

\section{Strengths of This Study}

The way incorporating SNA with Google Maps is unique when in comparison with those published papers [6-8] merely using a single SNA. Another strength and feature for this study is that Google Maps are used and linked in references [16-18] for interested readers who can manipulate the link by their own ways on the dashboards. The nation distribution in Figure 1 is merit in easily understanding the feature of international author collaborations on anesthesiology. One picture is worth ten thousand words. We hope following studies can report other kinds of information using Google API in future.

\section{LiMitATIONS AND FUTURE STUdY}

The interpretation and generalization of the conclusions of this study should be carried out with caution. First, the data of this study were collected from Medline for a single journal. It is worth noting that any attempt to generalize the findings of this study should be made in the similar fields of journal domains.

Second, although the data were extracted from Medline and carefully dealt with every linkage as correct as possible, the original downloaded text file including some errors in symbols such as period and comma in author address that might lead to some bias in the resulting nation distribution.

Third, there are many algorithms used for SNA. We merely applied separation components showing in Figures. Any changes made along with algorithm used will present different pattern and inference making.

Fourth, the social network analysis is not subject to the Pajeck software we used in this study, Others such as Ucinet[29] and Gephi[30] are suggested to readers for use in future. 


\section{CONCLUSION}

Social network analysis provides wide and deep insight into the relationships among nations, coauthor collaborations, and the keyword MESH terms. The results can be provided to readers for future submission to journal in anesthesiology.

\section{REFERENCES}

[1] American Society of Anesthesiologists. What is Anesthesiology. 2017/12/20 available at https:// goo.gl/nAxpXd

[2] Morris MA, Saboury B, Burkett B, Gao J, Siegel EL. Reinventing Radiology: Big Data and the Future of Medical Imaging.J Thorac Imaging. 2018 Jan; 33(1):4-16.

[3] Domingos p. A few useful things to know about machine learning. Communications of the ACM 2012; 55:10, 78-87.

[4] Verhoef PC, Kooge E, Walk N. Creating Value with Big Data Analytics: Making Smarter Marketing Decisions. London: Routledge, 2016.

[5] Power DJ..What is the "true story" about data mining, beer and diapers?DSS News. 2017/3/ 20 available at $h$ ttps://goo.gl/1FtGft

[6] Sadoughi F, Valinejadi A, Shirazi MS, KhademiR.Social Network Analysis of Iranian Researchers on Medical Parasitology: A 41 Year Co-Authorship Survey.Iran J Parasitol. 2016; 11(2):204-212.

[7] Osareh F, Khademi R, Rostami MK, Shirazi MS. Co-authorship Network Structure Analysis of Iranian Researchers' scientific outputs from 1991 to 2013 based on the Social Science Citation Index (SSCI). Collnet J Scientometr Info Manag. 2014; 8 (2): 263- 71.

[8] Liu X, Bollen J, Nelson ML, Van de Sompel H. Co-authorship networks in the digital library research community. Info Process Manag. 2005; 41 (6): $1462-80$.

[9] Dasgupta S, Vaughan AS, Kramer MR, Sanchez TH, Sullivan PS.Use of a Google Map Tool Embedded in an Internet Survey Instrument: Is it a Valid and Reliable Alternative to Geocoded Address Data?JMIR Res Protoc. 2014 Apr 10; 3(2):e24.

[10] Kobayashi S, Fujioka T, Tanaka Y, Inoue M, Niho Y, Miyoshi A.A geographical information system using the Google Map API for guidance to referral hospitals.J Med Syst. 2010 Dec; 34(6):1157-60.

[11] Osareh F, Khademi R, Rostami MK, Shirazi MS. Co-authorship Network Structure Analysis of Iranian Researchers' scientific outputs from 1991 to 2013 based on the Social Science Citation Index (SSCI). Collnet J Scientometr Info Manag. 2014; 8 (2): 263- 71.

[12] Holland PW, Leinhardt S. Transitivity in structural models of small groups". Comparative Group
Studies 1971; 2: 107-124.

[13] deNooy W, Mrvar A, Batagelj V. Exploratory Social Network Analysis With Pajek: Revised and Expanded, 2nd edn. New York, NY: Cambridge University Press, 2011.

[14] Phan TG, Beare R, Chen J, Clissold B, Ly J, Singhal S, Ma H, Srikanth V.Googling Service Boundaries for Endovascular Clot Retrieval Hub Hospitals in a Metropolitan Setting: Proofof-Concept Study.Stroke. 2017;48(5):13531361.

[15] Krackhardt D, Stern RN. Informal networks and organizational crises:An experimental simulation. Social Psychology Quarterly 1988; 51,123-140.

[16] Chien TW. Google Maps on the topic of author collaboration in anesthesiology. 2017/12/21 available at http://www.healthup.org.tw/gps/ Anesthesiology.htm

[17] Chien TW. Google Maps on eminent authors in anesthesiology. 2017/12/21 available at http:// www.healthup.org.tw/gps/Anesthesiologyauthor. $\mathrm{html}$

[18] Chien TW. Google Maps on MESH terms in anesthesiology. 2017/12/21 available at http:// www.healthup.org.tw/gps/Anesthesiologykey.ht m

[19] Leydesdorff L, Wagner C, Park HW, Adams J.International collaboration in science: the global map and the network.CoRR abs/1301. 0801 (2013)

[20] Glänzel W, Schlemmer B. National research profiles in a changing Europe (1983-2003) An exploratory study of sectoral characteristics in the Triple Helix. Scientometrics 2007; 70(2), 267-275.

[21] Erfanmanesh MA, Rohani VA, BasirianJahromi R, Gholamhosseinzadeh Z. Investigating Scientific Collaboration of Iranian Psychology and Psychiatry Researchers. J Info Process Manag.2013; 29 (1), 137-63.

[22] Osareh F, NorouziChakoli A, Keshvari M. Coauthorship of Iranian researchers in science, social science, art and humanities citation indexes in the web of science between 2000 and 2006. J Info Sci Technol.2010; 25 (4), 573-95.

[23] Hu SK, Huang J, Hong WD, Du XJ, Jin R, Lin TS. The 50 Most-cited Articles in Gastroenterology and Hepatology from Mainland China.Pak J Med Sci.2017; 33(1), 215-220.

[24] Coelho DH, Edelmayer LW, Fenton JE. A century of citation classics in otolaryngology-head and neck surgery journals revisited. Laryngoscope. 2014;.124(6).1358-1362.

[25] Holland PW, Leinhardt S. Transitivity in structural models of small groups. Comparative Group Studies 1971; 7-124.

[26] Watts DJ, Srogatz S. Collective dynamics of 'small-world' networks". Nature 1998;6684): 440-442.

[27] Chang HT, Lin MH, Hwang IH, Chen TJ, Lin HC, Hou MC, Hwang SJ. Scientific publications in 
gastroenterology and hepatology in Taiwan: Ananalysis of Web of Science from 1993 to 2013.J Chin Med Assoc.2017; 80(2), 80-85.

[28] Liu X, Bollen J, Nelson ML, Van de Sompel H. Co-authorship networks in the digital library research community. Info Process Manag. 2005; 41 (6): $1462-80$.
[29] Borgatti SP, Everett MG, Freeman LC. Ucinet for Windows: Software for Social Network Analysis. Harvard, MA: Analytic Technologies 2002.

[30] Bastian M, Heymann S, Jacomy M. Gephi: an open source software for exploring and manipulating networks. International AAAI Conference on Weblogs and Social Media, 2009.

Citation: Hsien-Yi Wang, Tsair-Wei Chien, Julie Chi Chow, Willy Chou. Applying Clustering Coefficient to the Pattern of International Author Collaboration in Anesthesiology. ARC Journal of Anesthesiology. 2017; 2(3):18-24. doi: dx.doi.org/10.20431/2455-9792.0203005.

Copyright: (c) 2017 Authors. This is an open-access article distributed under the terms of the Creative Commons Attribution License, which permits unrestricted use, distribution, and reproduction in any medium, provided the original author and source are credited. 